\section{La comunicación de los marginados invade la aldea global*. Folkcomunicación en la edad de Internet ${ }^{\star \star}$}

The communication of marginalized invades the global village. Folkcommunication in the Internet age

José Marques de Melo***

\section{Resumen}

Aunque sea un hecho universal, la Folkcomunicación -como sistema de expresión cultural de las clases subalternas o de los grupos marginados- recibe una atención más destacada de los investigadores en los países recién industrializados. En el caso emblemático de Brasil, el

* Conferencia magistral dictada en la V Bienal Iberoamericana de Comunicación realizada en el Instituto Tecnológico de Monterrey, Campus del Estado de México, en septiembre de 2005.

** Este artículo forma parte del libro: Yáñez Aguilar, C. et al. 2015 Folkcomunicación en América Latina: Diálogos entre Chile y Brasil. Temuco: Ediciones Universidad de La Frontera.

*** Profesor emérito de la Universidad de São Paulo y Director de la Cátedra UNESCO de Comunicación de la Universidad Metodista de São Paulo. estudio de su resistencia en territorio nacional respalda una disciplina académica, responsable por la construcción de un tipo de saber útil a la interacción eficaz entre cultura popular y comunicación masiva. Al contrario de las miradas apocalípticas de los que profetizaban su gradual agotamiento en la cumbre de la sociedad mediática, se trata de un campo de investigación que se hace fuerte y busca continua actualización. En verdad la Folkcomunicación enseña vigor en la edad digital. Anclados en un estudio de naturaleza exploratoria, pretendemos enseñar cómo ese sistema mediático contra-hegemónico viene potenciando la difusión mundial de las formas de sentir, pensar y actuar de las poblaciones económicamente excluidas, de las comunidades culturalmente marginadas, o de los grupos políticamente segregados.

Palabras clave: folkcomunicación, medios contra-hegemónicos, cultura popular, internet, Brasil.

\section{Abstract}

Although its performance as universal phenomena, the cultural system of expression used by the subaltern classes or marginalized groups, known as Folkcommunication, has had full scholarly attention almost only in the developing countries. In the singular case of Brazil, it was instituted an academic discipline useful for the linkage between popular culture and mass media. On the contrary of the apocalyptic forecast claiming its gradual weakness caused by the triumph of the media society, we indeed are testifying its resistance and update, by showing robustness in the digital age. Based on an exploratory research focusing the internet, this paper intends do explain how this contra hegemonic media system has increased the world 
diffusion of the feeling, thinking and acting forms played by the sectors economically excluded, the cultural marginalized communities and the political segregated groups.

Key words: folkcommunication, counter-hegemonic media, popular culture, internet, Brazil.

\section{Introducción}

El signo de la globalización acelerada se presenta como jalón de la grandeza del camino recorrido por la civilización en este inicio del siglo XXI. En la esfera político-económica, los encuentros anuales de Davos y Porto Alegre ofrecen nítidas evidencias del proceso mundializador. En el norte, agentes de la economía internacionalizada; en el sur, militantes políticos contrarios a la globalización. Las dos facciones van a las calles a gritar sus tesis y antítesis. Entretanto, las elites apenas incorporan esos eventos en su imaginario. Frente a ellos, las camadas populares actúan como meros espectadores.

No obstante, este fenómeno comporta otra dimensión, ni siempre perceptible. Éste repercute intensamente en las conversaciones familiares, penetrando en los grupos de la vecindad, por eso mismo son agregados al universo simbólico de las comunidades periféricas. Se trata de un mosaico cultural que los medios globalizados exhiben diariamente, rompiendo con el aislamiento social en el que los grupos marginados vivieran hasta ayer. Costumbres, tradiciones, gestos y comportamientos de otros pueblos, cercanos o distantes, circulan ampliamente en la aldea global. De la misma manera, padrones culturales que parecían sepultados en la memoria nacional, regional y local resurgen profusamente. Ellos permiten el rescate de celebraciones, ritos o fiestas aparentemente condenados al olvido, facilitando la interacción entre generaciones diferentes.

Se trata de un torbellino cultural que compara, distingue y mezcla símbolos de distintas naciones, regiones, ciudades, barrios y pueblos (Cochrane 1995), constituyendo la expresión contumaz de aquella riqueza del folclore mediatizado. Como evento singular, este fenómeno fue delineado en la teoría folkcomunicacional de Luiz Beltrão (1967). En verdad, este aporte brasileño corresponde a la secuencia de un episodio histórico protagonizado pioneramente por Marshal McLuhan en 1951 con la publicación de su obra Mechanical Bride. Con la argucia y la astucia que le eran típicas, el pensador canadiense se dio cuenta de esa mutación cultural y la rotuló como folklore del hombre industrial.

Hace medio siglo, por tanto, que el folklore de la sociedad industrial refleja la apropiación de la "cultura popular" por la poderosa "cultura de masas". Procesando símbolos e imágenes enraizadas en las tradiciones nacionales de los países hegemónicos, las industrias culturales las transforman en mercancías y las distribuyen para el consumo de las multitudes planetarias (Bausinger 1990 [1961]). De esta manera, el folklore mediático, típico de la sociedad post-industrial, se configura como amalgama de signos procedentes de distintas geografías nacionales o regionales, buscando proyectar culturas seculares o emergentes en el nuevo mapa del mundo.

Los espacios ocupados por las tradiciones populares en la agenda mediática contemporánea pueden traducir iniciativas destinadas a preservar identidades culturales amenazadas de exterminio o estagnación, cuando se hallan confinadas en territorios pretendidamente indes- 
tructibles. Pero también pueden funcionar como palanca para la renovación de las maneras de hacer, pensar y sentir de grupos o naciones que, empurrados coyunturalmente para el aislamiento mundial, han permanecido refractarios a la incorporación de novedades. En ese sentido, el folklore mediatizado tiene una doble faceta. De la misma manera que asimila ideas y valores procedentes de otros países, se preocupa de la proyección de las identidades nacionales, exportando contenidos que explicitan las singularidades de los pueblos aspirantes a ocupar los nuevos espacios creados en el panorama global.

Ramos (2004 [1952]) plantea la tesis de que Brasil, conocido como "laboratorio de civilización" donde el "mestizaje" se ha tornado paradigmático, sigue brindando evidencias de un "sincretismo" cultural continuamente renovado. Nuestra cultura nacional fue amalgamada por la conjunción de símbolos oriundos de rublos con múltiplas caras. El contingente lusitano nos ha ofrecido un legado híbrido de las tradiciones euro-latinas, incorporando trazos de civilización asimilados en los territorios africanos. Esta matriz hegemónica ha incorporado trazos inconfundibles de las poblaciones amerindias que habitaban nuestro litoral en los tiempos de la colonización, y que fueran expulsadas de la faja atlántica, sobreviviendo aisladamente en la selva amazónica y en otros focos bravíos. A ellas se sumarían las costumbres y expresiones de las comunidades africanas, traídas obligatoriamente en los navíos negreros para desempeñar funciones productivas en las plantaciones azucareras, en la pecuaria extensiva, o en los complejos auríferos.

De esa imbricación simbólica ha resultado una pujante cultura popular responsable en gran parte de la naturaleza de la identidad nacional bra- sileña. Ésta fue reproducida heterogéneamente durante cinco siglos en todos los cuadrantes de nuestra geografía. Sin embargo, los trazos explícitamente homogéneos de la llamada cultura brasileña son aquellos heredados de la cultura erudita euro-latina, diseminados sistemáticamente por la red escolar, la iglesia católica, y otras instituciones respaldadas por el aparato estatal.

Se trata de un dualismo cultural que fue cambiando, con el correr del siglo XX, por la penetración de padrones adecuados a la fisonomía polifacética de la emergente cultura de masas, importada de las matrices inicialmente europeas y, últimamente, de las industrias simbólicas norteamericanas (Marques de Melo 1970). Esa corriente ha tenido efectos significativos en la configuración de nuestro perfil cultural contemporáneo, que deja de reflejar el "archipiélago cultural" antes identificado por Manuel Diégues Junior (1960), proyectando aquella faceta que Renato Ortiz (1988) ha rotulado apropiadamente como la "moderna tradición brasileña".

Nos encontramos, por ende, en pleno proceso de transmutación de nuestra identidad cultural. Estamos compelidos a continuar importando padrones oriundos de las matrices de la industria mundial de bienes simbólicos, pero también participando de ese mercado internacional respaldado por la cultura masiva (Marques de Melo 1998).

\section{Presupuestos teóricos y metodológicos}

El mediólogo canadiense Marshal McLuhan ha debutado a mediados del siglo XX en el escenario intelectual norteamericano con la publicación del libro The Mechanical Bride (1951). En ese libro, McLuhan ha cumplido la tarea de 
explicitar la génesis de la cultura de masas, diseñando cómo los medios han configurado los sentidos de la sociedad norteamericana. Su investigación ha tomado como referencia los anuncios publicitarios y las piezas de entretenimiento (tebeos, cinema, televisión) difundidos por los diarios y las revistas periódicas.

En dicha obra estaba implícita la idea de que el "hombre industrial", viviendo en las periferias de las megalópolis, se ubicaba en una cultura de masas anclada en las tradiciones populares. Éste es innegablemente el "secreto" del éxito alcanzado por la industria mediática de los EE.UU. Sus raíces se asientan en el arsenal simbólico de las comunidades rurales edificadas por los antiguos colonizadores ingleses o en el legado cultural introducido por los contingentes de inmigrantes. Éstos formarían comunidades urbanas amalgamadas a la fuerte cultura popular norteamericana preservada por el aparato estatal, y respaldada, al mismo tiempo, por las agencias socializadoras presentes en todo el territorio nacional. Al masificarse esa cultura popular se fueron creando vínculos interactivos entre los yankees primitivos y los adventicios. De esa manera se preparaba el terreno hacia su exportación para todo el planeta, consubstanciando la aldea global.

En la misma coyuntura, en el norte de América, Marshall McLuhan formulaba hipótesis posteriormente confirmadas como realidades inequívocas, y en el sur del Ecuador, Luiz Beltrão diagnosticaba una situación diametralmente inversa. Brasil se perfilaba como una sociedad marcada por la vigencia de un sistema mediático elitista, ancorado en los valores de la cultura erudita, donde se expresaba la necesidad de decodificación de sus mensajes para que sean asimilados por las camadas populares de nuestra sociedad.
Este proceso de traducción de los contenidos mediáticos por los medios populares de información ha sido denominado por Beltrão (1967) como Folkcomunicación. Su tesis de doctorado ha estado dedicada a comprender las estrategias y los mecanismos adoptados por los agentes populares de comunicación en el sentido de tornar hechos inteligibles (informaciones), ideas (opiniones) y diversiones (entretenimiento). A través de investigaciones posteriores, Beltrão (1980) ha comprobado que la prensa, la radio, la televisión y el cine difunden mensajes que no logran la comprensión de vastos continentes poblacionales. Estos grupos "culturalmente marginados" reaccionan de manera no siempre ostensiva, robusteciendo un sistema mediático alternativo. Construyen y accionan vehículos artesanales o canales rústicos, muchas veces estableciendo también una especie de feedback en relación al sistema hegemónico.

Las investigaciones desarrolladas por los discípulos de Luiz Beltrão atestan contemporáneamente la riqueza de los procesos folkcomunicacionales en la base de nuestra sociedad. Sus resultados demuestran la persistencia de aquellos contingentes "marginados" de la sociedad de consumo, que demandan la decodificación "popular" de los contenidos elitistas difundidos por los medios convencionales (Benjamin 2000).

Hoy se evidencia también una corriente en el sentido opuesto, a saber, la incidencia de temas populares en los medios masivos, reflejando así la sensibilidad de los editores para responder a las expectativas de los segmentos que se incorporan a su mercado consumidor, principalmente el de la prensa diaria. Esos procesos folkmediáticos (Marques de Melo 2004a, 2004b) empiezan a ser desvendados por la nueva generación que integra 
la Red Brasileña de Investigadores de Folkcomunicación (Red Folkcom). Cuando evaluamos esta tendencia sudamericana, podemos concluir que estaríamos reproduciendo, medio siglo después, aquel mismo fenómeno que McLuhan identificara en el norte (Estados Unidos y Canadá) dándole el rótulo de "folclore del hombre industrial".

\section{La disciplina}

La Folkcomunicación configura un segmento innovador de la investigación latinoamericana en el ámbito de las ciencias de la comunicación. Se dedica especialmente a los estudios de los agentes y los medios populares de información de hechos y expresión de ideas (Beltrão 1967).

El objeto de esa nueva disciplina (Marques de Melo 2005) es situarse en la frontera entre el folklore (rescate e interpretación de la cultura popular) y la comunicación masiva (difusión industrial de los símbolos a través de medios mecánicos o electrónicos destinados a audiencias amplias, anónimas y heterogéneas). Si el folklore comprende formas grupales de manifestación cultural protagonizadas por las clases subalternas, la Folkcomunicación se caracteriza por la utilización de estrategias de difusión simbólica capaces de expresar en lenguaje popular mensajes previamente transmitidos por la industria cultural.

Luiz Beltrão (1980) comprendía la Folkcomunicación como un proceso de intermediación entre la cultura de las elites (erudita o masiva) y la cultura de las clases trabajadoras (rurales o urbanas). Dentro de esa perspectiva se promovieron las primeras investigaciones del género, privilegiando decodificaciones de la cultura de masas (o sus lecturas simplificadoras de la cultura erudita) hechas por vehículos rudimenta- rios, de los cuales se abastecen simbólicamente los segmentos populares de la sociedad.

Sin embargo, para legitimarse socialmente y para conquistar los mercados constituidos por los ciudadanos que no asimilan por completo la cultura alfabética, la industria cultural brasileña necesita retroalimentarse continuamente de la cultura popular. Muchos de sus productos típicos, principalmente en el sector del entretenimiento, rescatan símbolos populares, sometiéndolos a los padrones de la fabricación masiva y seriada. Esas apropiaciones son más comunes en los formatos de ficción o musicales.

La Folkcomunicación obtiene cada vez más importancia, por su naturaleza de instancia mediadora entre la cultura de masas y la cultura popular, protagonizando flujos bidireccionales y sedimentando procesos de hibridación simbólica. Ella representa incontestablemente una estrategia contra-hegemónica de las clases subalternas (Marques de Melo 1980). Se trata de una negociación al mismo tiempo sutil y astuciosa, según aquella acepción creada por el italiano Antonio Gramsci (1979) y reinterpretada por el brasileño Edison Carneiro (1965), que influenció decisivamente el planteamiento teórico construido por Luiz Beltrão.

\section{Los paradigmas}

Luiz Beltrão lanzó la plataforma de esta nueva disciplina en el ámbito de las ciencias de la comunicación en el primer número de la revista Comunicação \& Problemas el año 1965. En el artículo sobre el "ex -voto", el autor hizo una convocatoria a los investigadores de la comunicación para cambiar su mirada cognoscitiva. Era una invitación para focalizar un tipo de objeto que ya venía 
siendo competentemente estudiado por los antropólogos, sociólogos y folcloristas, pero olvidado por los comunicólogos (Marques de Melo 2003).

Su argumento implícito era que las manifestaciones populares, accionadas por los agentes de "información de hechos y expresiones de ideas", tenían tanta importancia comunicacional como aquellas difundidas por los medios masivos. Por eso recurría al arsenal metodológico ya testado y perfeccionado en el estudio de las manifestaciones convencionales del periodismo industrial (fabricadas de acuerdo con los canales postgutenbergianos), y las transportaba para analizar las ricas expresiones que sugería como integrantes del Folkperiodismo (transmitidas por canales pregutenbergianos o utilizando tecnologías tan rudimentarias como la prensa de Mogúncia).

En verdad, Beltrão había descubierto que los procesos modernos de comunicación masiva coexistían, en el espacio brasileño, con los fenómenos de la comunicación premoderna. Eran reminiscencias del período medieval-europeo transportadas por los colonizadores lusitanos, históricamente ubicadas en los nuevos tiempos, aparentando una especie de continuum simbólico. Aunque primitivos o artesanales, esos vehículos de comunicación popular, o de Folkcomunicación como él los prefirió denominar, actuaban como meros retransmisores o decodificadores de mensajes desencadenados por la industria de la comunicación masiva (periódicos, revistas, radio y televisión).

Todavía más, Beltrão había identificado teóricamente una afinidad entre esos procesos y aquellos que Elihu Katz y Paul Lazarsfeld (1955) habían observado en la sociedad norteamericana, descritos en el paradigma del "two-step-flowof-communication" (flujo de la comunicación en dos etapas). Las tesis de Luiz Beltrão represen- tarían, en realidad, un paso adelante en relación con los postulados de Katz y Lazarsfeld. Mientras ellos atribuyeron un carácter lineal e individualista al flujo de la comunicación en dos etapas, toda vez que resultaban dependientes de la acción persuasiva de los "líderes de opinión", el investigador brasileño tuvo la premonición de que el fenómeno era más complejo.

Este fenómeno comportaba una interacción bipolar (pues incluía el feedback protagonizado por los "agentes populares" en el contacto con los "agentes masivos"), y revelaba una naturaleza eminentemente colectiva. De esta manera, la reinterpretación de los mensajes no se hacía sólo en función de la "lectura" individual y diferenciada de los líderes de la comunidad, sino que además estaba sintonizada con las "normas de conducta" del grupo social, traduciendo el fuerte sentido de "cohesión" grupal. Al captar los signos de "cambio social", Beltrão demostraría el perfil típico de las sociedades que sufren las agruras del medio ambiente, necesitando transformarse para sobrevivir.

En cierto sentido, Luiz Beltrão anticipó observaciones empíricas que serían posteriormente profundizadas y compaginadas por la teoría de las "mediaciones culturales", el cerne de la contribución de Jesús Martín Barbero (1987) y de los culturalistas al pensamiento comunicacional latinoamericano. En esta corriente, el mexicano Jorge González (1990) ya había hecho referencia explícita a los estudios pioneros del científico brasileño sobre las clases subalternas. Esos estudios serían también reconocidos por el propio Jesús Martín Barbero (1999), específicamente en la ponencia sobre los "aportes" brasileños para las ciencias sociales de Latinoamérica que presentó en el XX Congreso Brasileño de Ciencias de la Comunicación (1997). 
En suma, Beltrão atribuiría a los agentes folkcomunicacionales -actuantes en las sociedades rurales o periféricas- un carácter nítidamente institucionalizado, aunque informal. Dicho carácter sería semejante a aquél que Barbero identificaría más tarde, de forma sistémica, en los agentes educativos, religiosos o políticos de las sociedades urbanas metropolitanas.

\section{La difusión}

Como toda propuesta innovadora, la Folkcomunicación de Luiz Beltrão ha enfrentado obstáculos para legitimarse. Hubo una doble resistencia: de los folkloristas conservadores, que pretendían defender la cultura popular de las investidas mediáticas modernizadoras; y de los comunicólogos radicales, que pretendían hacer de la cultura popular el caballo de Troya de sus batallas políticas, en lugar de aprender en esas manifestaciones genuinas el límite de la resistencia posible de comunidades empobrecidas, cuya meta es la superación de la marginalidad social.

Sin embargo, la historia tiene sus trampas imprevisibles. Lo que observamos hoy es justamente un movimiento en sentido inverso. Las evidencias niegan aquellas reacciones que vaticinaran el fin de las tradiciones rústicas. El objeto de estudio de la Folkcomunicación podría haber sido sepultado si la espiral de la postmodernidad lo hubiera tragado. Por el contrario, la globalización permite vislumbrar el escenario de un mundo polifacético y multicultural. Éste sugiere que cualquier inserción proactiva en su universo depende básicamente del capital simbólico acumulado en las mega, macro o micro regiones (Marques de Melo 2004a), potencialmente convertibles en imágenes y sonidos capaces de sensibilizar la aldea global por su carácter universal, en otras palabras: enraizados en la cultura popular, pero traducidos al lenguaje de la cultura de masas.

Ésta es indudablemente la actualidad del pensamiento comunicacional de Luiz Beltrão. Él ha pensado, en la era de McLuhan, sobre las interacciones entre la aldea local y la aldea global, construyendo un referencial teórico consistente, que ha lanzado puentes entre los folkmedia y los massmedia. Beltrão ha reconocido el universal que subsiste en la producción simbólica de los grupos populares, percibiendo al mismo tiempo que los dos sistemas comunicacionales continuarán articulándose en una suerte de feedback dialéctico, continuo, creativo. Su legado intelectual se ha diseminado en todo el territorio nacional, conquistando seguidores que han llenado lagunas de sus ideas seminales o que han avanzado en los senderos empíricos por él abiertos (Marques de Melo 2005).

Además de los sucesores inmediatos como Roberto Benjamin (2004, 2000), Joseph Luyten (2003, 2001, 2000), José María Tenório (2004, 1998), Oswaldo Trigueiro $(2004,2002,2001)$ y Sebastião Breguez $(2004,2001)$, florece una segunda generación de investigadores de los fenómenos folkcomunicacionales, entre los cuales se proyectan Severino Lucena $(2004,1998)$, Antonio Teixeira Barros (2004, 2001, 2000), Marlei Sigrist (2004, 2002), Samantha Castelo Branco (2005, 2000, 1997), Cristina Schmidt (2004, 2001, 2000), Antonio Hohlfeldt (2004a, 2002b, 2002), Maria Cristina Gobbi (2005, 2004), Maria Érica de Oliveira (2000), Daniel Galindo (2001, 2000, 1999), Elizabeth Gonçalves (2005, 1999), Rosa Nava (2001), Waldemar Kunsch (2000, 1998), Maria das Graças Targino (2000), Sergio Gadini y Zeneida Assumpção (2004, 1999), Karina WoitowiCz (2001), Betânia Maciel (2005, 1999), Mariana Mesquita (2000), Alfredo D'Almeida (2002), Ro- 
sangela Marçolla (2002), Orávio Campos Soares $(2004,2003)$ y Tamara Brandão $(2005,2004)$.

Las ideas de estos sucesores están siendo rescatadas, actualizadas y profundizadas por la Red Folkcom -Red Brasileña de Folkcomunicación, constituida con el apoyo de la Cátedra UNESCO/UMESP de Comunicación para el Desarrollo Regional. Se trata de un colectivo de investigadores/as abocados/as al estudio de las interfaces entre comunicación masiva y cultura popular que se reúne anualmente en las Conferencias Brasileñas de Folkcomunicación, ya desde hace una década. El acervo hoy constituido por centenas de investigaciones empíricas y reflexiones críticas fue producido para los encuentros de São Bernardo do Campo (1998), São João del Rei (1999), João Pessoa (2000), Campo Grande (2001), Santos (2002), Campos de Goytacazes (2003), Lajeado (2004) e Teresina (2005). La memoria de esos eventos acaba de ser reunida y abierta para consulta pública en la Enciclopedia del Pensamiento Comunicacional en Latinoamérica, una iniciativa lanzada por la Cátedra UNESCO de Comunicación de Brasil $^{1}$. Adicionalmente, la Red Folkcom, en conjunto con la Universidad Estadual de Ponta Grossa, está editando también una publicación electrónica denominada Revista Internacional de Folkcomunicación ${ }^{2}$.

En el plan latinoamericano, el pensamiento de Luiz Beltrão ha inspirado las producciones científicas del Grupo de Estudios de Folkcomunicación creado por ALAIC -Asociación Latinoamericana de Investigadores de la Comunicación- y coordinado por uno de sus discípulos más actuales, el Dr. Roberto Emerson da Câmara Be-

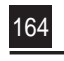

Se puede conocer en: www.metodista.br/unesco/encipecom Se pude aceder a través de: http://www.uepg.br/revista- jamin. El primer encuentro de los estudiosos latinoamericanos de Folkcomunicación ocurrió en el $4^{\circ}$ Congreso de ALAIC realizado en la ciudad de Recife, ocasión en que se lanzó una obra colectiva sobre la vida y obra del maestro de Pernambuco: Itinerário de Luiz Beltrão (AIP/UNICAMP 1998). Tres otros encuentros de este grupo fueron realizados en Santiago, Chile (2000), Santa Cruz de la Sierra, Bolivia (2002) y La Plata, Argentina (2004). La siguiente reunión está prevista en São Leopoldo, Brasil (2006).

\section{Proyección en Internet}

Si la disciplina académica viene experimentando tamaña expansión, más significativa ha sido la trayectoria de la Folkcomunicación en los espacios propiciados por la Internet. Este territorio se ha mostrado fértil, principalmente para la germinación y el cultivo de relatos sobre las actividades desarrolladas por los agentes folkcomunicacionales, ampliando considerablemente sus rayos de acción. Además de garantizar la continuación de varios géneros o formatos de expresión popular, la web permite multiplicar sus interlocutores, así como proporcionar oportunidad para el intercambio entre grupos y personas que poseen identidades comunes, aunque distanciados por la geografía.

Buscando comprobar esta proposición, hicimos un rastreo de palabras claves en el banco de datos mantenido por Google, lo que ha mostrado resultados inesperados. Procuramos saber inicialmente cuál era la amplitud de las fuentes disponibles en Internet sobre Folkcomunicación como disciplina académica. Encontramos 1.118 referencias, siendo 823 alusivas a la propia disciplina y 295 a su fundador Luiz Beltrão. 
Seguidamente, buscamos conocer el tamaño del espacio ocupado por los fenómenos típicamente folkcomunicacionales, aquellos que señalizan los objetos de estudio de los investigadores académicos. Experimentamos entonces una grande sorpresa al constatar que el universo empírico era casi mil veces superior al campo teórico. Encontramos 960.891 referencias que tenían por foco principal los tipos de folkcomunicación situados en diferentes ámbitos de la vida cotidiana.

Trabajamos con una matriz taxonómica construida a partir del ejercicio clasificatorio de la Folkcomunicación (Marques de Melo 1979), sometido a la crítica de los participantes del Primer Congreso Nacional de Ciencias de la Comunicación (INTERCOM 1978), en ese entonces acogido por el fundador de la disciplina. Al elaborar el documento "Indicador y bibliografía sumaria para la investigación en Folkcomunicación", Beltrão remite "al estudio de la bibliografía reunida por Marques de Melo, en su ensayo sobre la disciplina "Sistemas de Comunicación en Brasil””' (1980: 278).

Esa clasificación contemplaba cuatro géneros folkcomunicacionales: escrito, oral, icónico y cinético. En esa coyuntura histórica, nos damos cuenta que dicha clasificación puede ser útil para reconocer la naturaleza de los objetos folkcomunicacionales que, rompiendo la barrera del milenio, se proyectaban al futuro. Entonces, creímos insuficiente el ámbito contemplado para el género "folkcomunicación escrita", decidiendo ampliarlo bajo la denominación de "folkcomunicación visual". La intención fue agrupar las expresiones propiamente lingüísticas a aquellas otras que embutían representaciones pictóricas y demás símbolos visuales.
De esa manera, tratamos de identificar, en el cuerpo de cada "género" y de cada "formato", cuáles eran los "tipos" que poseían afinidades simbólicas. A partir de los indicadores bibliográficos disponibles en los más recientes estudios folkcomunicacionales (Gobbi 2004), ampliamos el elenco original (Marques de Melo 1979), justamente para dar cuenta de un sistema de comunicación que ha adquirido mayor complejidad en las interfaces que hace dinámicamente con el sistema hegemónico de la "comunicación masiva" (Beltrão y Quirino 1986), y con el sistema histórico de la "comunicación erudita" (Beltrão 1972).

Los resultados obtenidos a través del levantamiento de las palabras claves correspondientes a los "tipos folkcomunicacionales" referenciadas por Google a partir de su base de fuentes digitalizadas, permitieron constatar las siguientes evidencias:

Tabla 1. Referencias agrupadas según géneros folkcomunicacionales

\begin{tabular}{|l|c|c|}
\hline \multicolumn{1}{|c|}{$\begin{array}{c}\text { Géneros } \\
\text { folkcomunicacionales }\end{array}$} & N.A & $\%$ \\
\hline Folkcomunicación oral & 146.389 & 15.2 \\
\hline Folkcomunicación visual & 351.972 & 36.7 \\
\hline Folkcomunicación icónica & 10.757 & 1.1 \\
\hline Folkcomunicación cinética & 451.773 & 47.0 \\
\hline Total & $\mathbf{9 6 0 . 8 9 1}$ & $\mathbf{1 0 0 . 0}$ \\
\hline
\end{tabular}

Fuente: Levantamiento realizado en Google (junio 2005).

Llama la atención el volumen representado por el género cinético (casi la mitad del espacio total) y por el género visual (33.9\%). Juntos, ellos significan aproximadamente 8 de cada 10 referencias acumuladas. Verificamos, en los dos casos, la predominancia de algunos formatos singulares, ostensivamente desnivelados en 
relación con la media de las manifestaciones congéneres. Esa tendencia se confirma también en el interior de los géneros minoritarios: el tipo que encabeza la lista de referencias al interior de cada género ocupa espacios que varían de dos tercios (caso del género icónico) a la mitad (casos de los géneros oral y musical).

¿Cuáles son los tipos folkcomunicacionales que conquistan más espacio en Internet? Ese panorama puede ser esbozado con mayor nitidez a partir de la composición de los tipos mayoritarios con los minoritarios.

Tabla 2. Géneros de la folkcomunicación oral

\begin{tabular}{|l|l|}
\hline Principales tipos & Número de referencias \\
\hline Leyenda & 36.400 \\
\hline Canto de trabajo & 30.400 \\
\hline Trova & 23.300 \\
\hline Llanto & 21.100 \\
\hline Baião & 8.920 \\
\hline
\end{tabular}

Tabla 3. Géneros de la folkcomunicación visual

\begin{tabular}{|l|l|}
\hline Principales tipos & Número de referencias \\
\hline Tatuaje & 327.000 \\
\hline Literatura de cordel & 10.300 \\
\hline Estampas de propaganda & 1.440 \\
\hline Xilograbado popular & 1.290 \\
\hline Petición colectiva & 1.270 \\
\hline
\end{tabular}

Tabla 4. Géneros de la folkcomunicación icónica

\begin{tabular}{|l|l|}
\hline Principales tipos & Número de referencias \\
\hline Ex-voto & 7.940 \\
\hline Amuletos & 799 \\
\hline Presepio & 788 \\
\hline Muñeco de barro & 388 \\
\hline Juguete artesanal & 375 \\
\hline
\end{tabular}

Tabla 5. Géneros de la folkcomunicación cinética

\begin{tabular}{|l|l|}
\hline Principales tipos & Número de referencias \\
\hline Funk carioca & 143.000 \\
\hline Rap paulista & 57.200 \\
\hline Ferias de ganaderos & 52.600 \\
\hline Forró nordestino & 25.700 \\
\hline Mitin electoral & 24.000 \\
\hline
\end{tabular}

Si bien las tablas anteriores muestran cómo los diversos tipos están relacionados por orden de grandeza con sus congéneres, dentro de cada género se torna indispensable ultrapasar esa ubicación al interior de cada categoría para darse cuenta claramente de cuáles son los tipos que poseen mayor densidad en los acervos documentales referenciados por Internet.

A continuación se presentan los tipos más referenciados en cada género, retirando las fronteras que los separan temáticamente.

Tabla 6. Formatos más referenciados en Internet ${ }^{3}$

\begin{tabular}{|l|l|}
\hline Principales tipos & Número de referencias \\
\hline Tatuaje & 327.000 \\
\hline Funk carioca & 143.000 \\
\hline Rap paulista & 57.200 \\
\hline Feria de ganaderos & 52.600 \\
\hline Leyenda & 36.400 \\
\hline Canto de trabajo & 30.400 \\
\hline Forró nordestino & 25.700 \\
\hline Mitin electoral & 24.000 \\
\hline Llanto & 21.100 \\
\hline Literatura de cordel & 10.300 \\
\hline Baião & 8.920 \\
\hline Ex-voto & 7.940 \\
\hline Estampas de propaganda & 1.440 \\
\hline Xilograbado popular & 1.290 \\
\hline Petición colectiva & 1.270 \\
\hline Canturia & 848 \\
\hline Amuletos & 799 \\
\hline Presépio & 788 \\
\hline Muñeco de barro & 388 \\
\hline Juguete artesanal & 375 \\
\hline & \\
\hline
\end{tabular}


Impresiona la importancia cuantitativa que asumen los tipos más sintonizados con las demandas culturales de los/as jóvenes (usuarios principales de Internet). Se confirma, de cierta manera, la tendencia ya esquematizada por Beltrão (1980), que ha identificado como los agentes principales de la folkcomunicación, en el final del siglo pasado, a los grupos culturalmente marginados de la sociedad, engrosando aquellos contingentes de contestación a los principios, a la moral o a la estructura social vigente.

No es sin razón que tipos poco anclados en las raíces históricas de la cultura brasileña -como los tatuajes, el funk carioca o el rap paulistaasumen la vanguardia folkcomunicacional en este nuevo milenio. A ellos se agregan los tipos consubstanciados en aquellas aspiraciones de entretenimiento colectivo, excitante y módico a un solo tiempo -como las ferias de ganaderos y el forró- disfrutando el sonido de ritmos mestizos -como el llanto y el baião-. Se destacan también los tipos que pueden traducir gritos de protesta o lamento de las camadas segregadas por los prejuicios de las elites como los mitines electorales, las peticiones coletivas, las estampas de propaganda o los cantos de trabajo-.

Se trata, en el conjunto, de tipos que reflejan innegablemente los trazos de aquella "moderna tradición" a la que se refería Renato Ortiz (1988), determinantes de la nueva fisonomía de la sociedad brasileña, hoy más influenciada por las corrientes culturales made in USA. Persisten, sin embargo, diversos formatos y tipos folkcomunicacionales anclados en las tradiciones latinas o ibéricas, como las leyendas, la literatura

$3 \quad$ Por orden de relevancia cuantitativa en el interior de cada género folkcomunicacional. de cordel, la canturia y el xilograbado popular. De la misma manera, se mantienen vigentes modos de expresión legitimados por la religiosidad rústica -como los ex-votos, o los amuletos y los presepios-. Aunque con menor intensidad, aparecen los formatos lúdicos como los muñecos de barro y los juguetes artesanales.

\section{La punta del iceberg}

Los datos obtenidos a través de esa investigación exploratoria sugieren desdoblamientos empíricos, analíticos o reflexivos. Ellos han sido tejidos justamente con la intención de motivar a otros investigadores, situados en distintos espacios geográficos, a proseguir en este itinerario, elucidando enigmas o interpretando contrastes.

Reiteramos que, mientras exegetas apresados tengan consideradas las nuevas tradiciones populares como residuos en extinción, en verdad el estudio de la folkcomunicación subsiste ampliamente, perdurando y renovándose en este nuevo milenio. Con capacidad de amplificar el acervo cognitivo y el bagaje cultural de los grupos marginados y de los contingentes excluidos, la red mundial de computadoras propicia condiciones para la actualización dinámica de esta nueva disciplina. Los géneros, formatos y tipos folkcomunicacionales fluyen regularmente a través de la web. Sin perder las identidades que les dan sentido histórico y vigor intelectual, ellos ganan difusión más adelante de las fronteras en que germinaran y florecieran.

Justamente en función de la transparencia, intensidad y diversidad adquiridas por los fenómenos folkcomunicacionales, nuevos estudios son necesarios para comprender mejor su dinámica en la sociedad digital. Se trata de un 
desafío que puede ser enfrentado por los/as jóvenes investigadores/as, casi siempre deseosos/as de explorar objetos aún en fase de configuración en el organismo social.

En esa corriente ya se destacan algunos de los/as investigadores/as brasileños/as. Rosângela Marçola (2002) procura comprender el modo como los "contadores de historias" diseminan mitos y leyendas a través de Internet. Aparecida Ribeiro dos Santos y Lana Cristina Nascimento dos Santos (2002) exploran los territorios allí ocupados por las "religiones populares". A su vez, Daniel Galindo, Celeste Ribeiro y Vânia Braz de Oliveira (2005) desvendan las estrategias utilizadas por los gobiernos locales en el sentido de fomentar el turismo municipal, seduciendo visitantes a través del potencial folklórico de las respectivas ciudades.

Sin embargo, sólo a través de la realización de análisis comparativos será posible construir generalizaciones susceptibles de credibilidad. Extendemos una invitación a los/as investigadores/as para que incluyan objetos fokcomunicacionales en sus agendas, toda vez que nuestra meta es elaborar un mapa iberoamericano de esas formas de expresión popular.

\section{Bibliografía}

Barbero, J. M. 1999. "Lo que la investigación latinoamericana de comunicación debe al Brasil". Vinte anos de ciências da comunicação no Brasil. Lopes, M. I. (Org.). São Paulo: INTERCOM. 32-48. D.F.: Gustavo Gili. 1987. De los medios a las mediaciones. México

Barreto, L. A. 1994. Um novo entendimento do folclore. Aracaju: Sociedade Editorial de Sergipe.

Barros, A. 2004. "Folkcomunicação na cidade: Cenários urbanos, herança rural". Signos 25 (1): 69-78.

2001. "O misticismo assume o lugar do folclore em Brasília?”. Anuário Unesco/Umesp de Comunicação Regional 5: 197-212.

2000. "Relações públicas e folkcomunicação: Reflexões à luz da teoria da ação comunicativa". Comunicação \& Sociedade 34: 129-144.

Bausinger, H. 1990 [1961]. Folk Culture in a World of Technology. Indiana: Indiana University Press.

Beltrão, L. y Quirino, N. 1986. Subsídios para uma teoria da comunicação. São Paulo: Summus.

1980. Folkcomunicação. A comunicação dos marginalizados. São Paulo: Cortez.

1972. Sociedade de massa: Comunicação \& literatura. Petrópolis: Vozes.

1967. Folkcomunicação. Um estudo dos agentes e dos meios populares de informação de fatos e expressão de idéias. Tese de Doutorado. Brasília: Universidade de Brasília.

Benjamin, R. 2004. Folkcomunicação na sociedade contemporânea. Porto Alegre: Comissão Gaúcha de Folclore. 2000. Folkcomunicação no contexto de massa. João Pessoa: Editora da Universidade Federal da Paraíba.
Brandão, T. 2005. Comunicação, cultura e mídia: O mito do unhudo da pedra branca. Dissertação de Mestrado. Faculdade de Arquitetura, Artes e Comunicação: UNESP-Bauru.

2004. "Folkcomunicação da Latrina: Estudo dos sanitários da UNESP-Bauru”. Folkcomunicação: Resistência cultural na sociedade globalizada. Breguez, S. (Org.). Belo Horizonte: INTERCOM. 185-196.

Breguez, S. 2004. Folkcomunicação: Resistência cultural na sociedade globalizada. Belo Horizonte: INTERCOM.

2001. "Tiradentes, a festa cívica da liberdade". Anuário Unesco/Umesp de Comunicação Regional 5: 151-156.

Castelo, S. 2005. "Metodologia folkcomunicacional: Teoria e prática". Métodos e técnicas de pesquisa em comunicação. Duarte, J. y Barros, A. (Orgs.). São Paulo: Atlas. 110-124.

2000. "Imagens midiáticas do Carnaval Brasileiro, João Pessoa". Anais da II Conferência Brasileira de Folkcomunicação. São João dele Rei: UNIREI.

1997. "Novela do Judas sem a morte da cultura popular: A convivência entre os sistemas culturais". Comunicação \& Sociedade 27: 123-135.

Carneiro, E. 1965. A dinâmica do folclore. Rio de Janeiro: Civilização Brasileira.

Cochrane, A. 1995. "Global Worlds and Worlds of Difference". A Global World? Anderson, B. y Cochrane, A. (Eds.). New York: Oxford University Press. 249-280.

D’Almeida, A. 2002. "Caravana Farkas: Uma simbiose entre cinema documentário e folkcomunicação”. Idade Mídia 2: 57 66. neiro: MEC-INEP.

Diégues, M. 1960. Regiões culturais do Brasil. Rio de Ja-

Gadini, S. y Assumpção, Z. 2004. "A cultura ucraniana na 
radiodifusão paranaense: Folclore e expressão midiática da cultura dos grupos étnicos". Signos 25 (2): 29-44.

1999. "Mídia e folclore da comunicação Russa no Paraná". Anais da Il Conferência Brasileira de Folkcomunicação. São João dele Rei: UNIREI.

Galindo, D., Ribeiro, C. y Oliveira, V. B. 2005. "Cidades na web e folclore na rede: A transposição do folclore na Internet”. VIII Conferência Brasileira de Folkcomunicação. Teresina: CEUT. 2001. "A festa do Peão Boiadeiro. Barretos, São Paulo". Anuário Unesco/Umesp de Comunicação Regional 5: 157182

2000. "Magic Park, Aparecida: O profano e o sagrado mediados pela cultura do lazer". Comunicação \& Sociedade 34: $161-180$

y Gonçalves, E. 1999. "O ET de Varginha: Entre o fato, a ficção e o folclore". Anais da Il Conferência Brasileira de Folkcomunicação. São João dele Rei: UNIREI.

Gobbi, M. C. 2005. "Luiz Beltrão e a Folkcomunicação: Estímulo para as novas gerações". VIII Conferência Brasileira de Folkcomunicação. Teresina: CEUT.

2004. "Bibliografia de Folkcomunicação". Folkcomunicação: Teoria e metodologia. Beltrão, L. (Org.). São Bernardo do Campo: Editora UMESP. 143-160.

Gonçalves, E. 2005. "O Folclore na mídia de massa: Globo rural e aspectos folclóricos do homem do campo". VIII Conferência Brasileira de Folkcomunicação. Teresina: CEUT.

González, J. 1990. Sociología de las culturas subalternas. Mexicali: Universidad Autónoma de Baja California.

Gramsci, A.1979. "History of the Subaltern Classes: Methodological Criteria". Communication and Class Struggle. Vol. I. Mattelart, A. y Siegelaub, S. (Orgs.). Paris: IMMRC. 90-91.

Hohlfeldt, A. 2004. "A imagem da política e dos políticos na perspectiva da Folkcomunicação: Uma abordagem exploratória". Anuário Unesco/Umesp de Comunicação Regional 8: 59-78. 2002a. "Folkcomunicação: Sadio oportunismo de quase meio século". Anuário Unesco/Umesp de Comunicação Regional 5: 25-34.

2002b. "Novas tendências nas pesquisas de folkcomunicação: Pesquisas acadêmicas se aproximam dos estudos culturais". XXV Congresso Brasileiro de Ciências de Comunicação. Salvador: INTERCOM.

Katz, E. y Lazarsfeld, P. F. 1955. Personal Influence: The Part Played by People in the Flow of Mass Communications. New York: The Free Press.

Kunsch, W. 2000. "Uma contribuição para os estudos de folkcomunicação". Comunicação \& Sociedade 34: 129-144. 1998. De Belém a Bagé: Imagens midiáticas do natal brasileiro. São Bernardo do Campo: Editora UMESP.

Lucena, S. 2004. "Do ex-voto ao folkmarketing". Folkcomunicação: Resistência cultural na sociedade globalizada. Breguez, S. (Org.). Belo Horizonte: INTERCOM. 55-66.

. 1998. Azulão do Bandepe. Recife: Edição do autor.

Luyten, J. 2003. "A Comparative Analysis of Latin América Popular Poetry”. Anuário Unesco/Umesp de Comunicação Regional 7: 15-50.

2001. "O conceito de Folkcomunicação". Mídia e folclore. Marques de Melo, J. (Org.). Maringá: Faculdades Maringá 29-30.

2000. "Folkcomunicação no contexto de massa". Comunicação \& Sociedade 34: 211-215.

Maciel, B. 2005. "Os caminhos que levam à Meca do Catolicismo Rústico". Anais da VIII Conferência Brasileira de Folkcomunicação. Teresina: CEUT.

1998. "Comunicação e crença: Mitos e rituais". Anais da II Conferência Brasileira de Folkcomunicação. São João dele Rei: UNIREI.

Marçolla, R. 2002. "Os cantadores e suas histórias na Internet”. Idade Mídia 2: 39-56.

Marques de Melo, J. 2005. "Folkcomunicação, disciplina com sotaque brasileiro". Anuário Internacional de Comunicação Lusófona 3: 73-86.

São Paulo: Paulus. 269-272.

2004a. "O folclore midiático". A esfinge midiática. 2004b. "Comunicação, região, desenvolvimento". Comunicação, região \& desenvolvimento. Marques de Melo, J. et al. (Orgs.). Campo Grande: UNIDERP. 19-26.

São Paulo: Paulus.

2003. História do pensamento comunicacional.

1998. "Uma nova ordem midiática mundial: Realidade/ficção? (A utopia de MacBride e as telenovelas brasileiras)". Teoria da comunicação: Paradigmas latino-americanos. Petrópolis: Vozes. 387-404.

Paulo: Cortez

1980. Comunicação e classes subalternas. São

1979. "Sistemas de Comunicação no Brasil". Ideologia e poder no ensino de comunicação. Marques de Melo, J., Fadul, A. M. y Lins Da Silva, C. A. (Orgs.). São Paulo: Cortez \& Moraes-INTERCOM. 211-239.

trópolis: Vozes

1970. Comunicação social: Teoria e pesquisa. Pe-

McLuhan, M. 1951. The Mechanical Bride. Folklore of the Industrial Man. Boston: Beacon Press.

Mesquita, M. 2000. "Folkcomunicação e hibridação cultural: Interação de aportes para pensar a cultura popular". Comunicação \& Sociedade 34: 145-160.

Nava, R. 2001. "Persistência do ex-voto na sociedade tecnológica, Campo Grande". Anais da IV Conferência Brasileira de Folkcomunicação. Campo Grande: UFMS.

Oliveira, M. É. 2000. "Religiosidade na ópera sertaneja". Anais da III Conferência Brasileira de Folkcomunicação. João Pessoa: UFPB. Brasiliense.

Ortiz, R. 1988. A moderna tradição brasileira. São Paulo:

Ramos, A. 1952. A mestiçagem no Brasil. Maceió: Editora da UFAL.

Santos, A. R. y Santos, L. C. N. 2002. "A religiosidade popular na Internet”. Idade Mídia 2: 27-38.

Schmidt, C. 2004. "Consolidação acadêmica da folkcomunicação: A cultura como objeto de estudo comunicacional". Pensamento comunicacional latino-americano: Da pesquisa denúncia ao pragmatismo utópico. Marques de Melo, J. y Gobbi, M. C. (Orgs.). S. B. do Campo: Editora UMESP. 201-210. 
2001. "O comunicador folk das festas de uma só". Anuário Unesco/Umesp de Comunicação Regional 5: 35-32.

2000. "A transdisciplinaridade na pesquisa dos modos culturais híbridos". Anais da III Conferência Brasileira de Folkcomunicação. João Pessoa: UFPB.

Sigrist, M. 2004. "Co-existência pacífica da tradição com a modernidade". Folkcomunicação: Resistência cultural na sociedade globalizada. Breguez, S. (Org.). Belo Horizonte: INTERCOM. 43-54. 2002. "Carnaval transfronteiras no Brasil". Anuário Unesco/Umesp de Comunicação Regional 5: 43-59.

Soares, O. C. 2004. Muata Calombo, consciência e destruição. Campos: Editora FAFIC.

2003. "Mana Chica do Caboclo: Representação cultural da Baixada Campista". Anais da VI Conferência Brasileira de Folkcomunicação. Campos: Editora FAFIC.

Targino, M. D. G. 2000. "O carnaval no contexto da mídia piauiense". III Conferencia Brasileira de Folkcomunicação. João Pessoa: UFPB.
Tenório, J. M. 2004. "O mito da loira de Aracaju". Folkcomunicação: Resistência cultural na sociedade globalizada. Breguez, S. (Org.). Belo Horizonte: INTERCOM. 137-148.

1998. "Bode na Cabeça, as "forças ocultas" na política do Pilar". Anais da I Conferência Brasileira de Folkcomunicação. São Bernardo do Campo: UMESP.

Trigueiro, O. 2004. Quando a televisão vira outra coisa. Tese de Doutorado. São Leopoldo (RS): Universidade do Vale dos Sinos (RS).

2002. "Agonia e morte de Frei Damião na mídia e no cordel". Anuário Unesco/Umesp de Comunicação Regional 6: $105-122$.

2001. "São João de Campina Grande na mídia". Anuário Unesco/Umesp de Comunicação Regional 5: 135-150.

Woitowicz, K. 2003. "Dança de um passado negro. Relações entre folclore e cultura popular na preservação da cultura religiosa na Congada da Lapa - PR". Anais da VI Conferência Brasileira de Folkcomunicação. Campos: FAFIC. 